\title{
Protective Effects and Mechanism of Radix Polygalae Against Neurological Diseases as Well as Effective Substance
}

\author{
Ning Jiang ${ }^{1,2}$, Shanshan Wei ${ }^{1}$, Yiwen Zhang ${ }^{2}$, Wenlu $\mathrm{He}^{1}$, Haiyue $\mathrm{Pe}^{2}$, Hong Huang ${ }^{2}$, \\ Qiong Wang ${ }^{1,3 *}$ and Xinmin Liu ${ }^{1,2 *}$ \\ ${ }^{1}$ Sino-Portugal TCM International Cooperation Center, The Affiliated Traditional Chinese Medicine Hospital of Southwest \\ Medical University, Luzhou, China, ${ }^{2}$ Research Center for Pharmacology and Toxicology, Institute of Medicinal Plant \\ Development (IMPLAD), Chinese Academy of Medical Sciences and Peking Union Medical College, Beijing, China, ${ }^{3}$ Institute \\ of Food Science and Technology, Chinese Academy of Agricultural Sciences (CAAS), Beijing, China
}

OPEN ACCESS

Edited by:

Lawrence Toll,

Florida Atlantic University United States

Reviewed by:

Sungho Maeng.

Kyung Hee University, South Korea

Rosalia Crupi,

University of Messina, Italy

*Correspondence:

Xinmin Liu

liuxinmin@hotmail.com

Qiong Wang

luyiwangqiong@163.com

Specialty section:

This article was submitted to

Psychopharmacology,

a section of the journal

Frontiers in Psychiatry

Received: 31 March 2021 Accepted: 27 September 2021 Published: 17 December 2021

Citation:

Jiang N, Wei S, Zhang Y, He W, Pei H, Huang H, Wang $Q$ and Liu X (2021) Protective Effects and Mechanism of Radix Polygalae Against Neurological Diseases as Well as Effective

Substance.

Front. Psychiatry 12:688703. doi: 10.3389/fpsyt.2021.688703
Radix Polygalae (also known as Yuanzhi in China) is the dried rhizome of Polygala tenuifolia Willd. or Polygala sibirica L., which is a famous Chinese herb and has been widely used for centuries in traditional medicines including expectorants, tonics, tranquilizers, antipsychotic, and so on. This article reviews the neuroprotective effects of Radix Polygalae in preclinical models of central nervous system (CNS) disorders, especially anxiety, depression, declining cognition, Alzheimer's disease (AD), and Parkinson's disease (PD). The chemical composition of Radix Polygalae as well as the underlying mechanisms of action were also reviewed. We found that Radix Polygalae possesses a broad range of beneficial effects on the abovementioned conditions. The multifold mechanisms of action include several properties such as antioxidant and associated apoptotic effects; anti-inflammatory and associated apoptotic effects; neurogenesis, regeneration, differentiation, and neuronal plasticity improvement; hypothalamic-pituitary-adrenal axis (HPA) regulation; neurotransmitter release; and receptor activation $\left(A_{2 A} R\right.$, NMDA-R, and GluR). Nevertheless, the detailed mechanisms underlying this array of pharmacological effects observed in vitro and in vivo still need further investigation to attain a coherent neuroprotective profile.

Keywords: neurological diseases, protective effects, review, animal, Radix Polygalae

\section{INTRODUCTION}

The central nervous system (CNS) is the most important regulatory system in the human body, playing a leading role in various life systems. With the continuous development of society and economy and the acceleration of industrialization and urbanization, the pressure of social competition is increasing and the pace of peoples' lives is also speeding up. Consequentially, there is an increasing prevalence of neurological disease, especially for mental disorders such as anxiety, depression, cognitive dysfunction, and neurological conditions such as Alzheimer's disease (AD) and Parkinson's disease (PD) (1,2). According to the World Health Organization, the lifetime prevalence and 12-month prevalence rate of anxiety disorders worldwide were 5-25 and $3.3-20.4 \%$, respectively, and major depression was listed as the third-highest cause of the global disease burden in 2008 and was predicted to take the lead by $2030(3,4)$. In 2015, the number of patients with $\mathrm{AD}$ reached 46.8 million worldwide, and by 2050 , the number of patients with 
$\mathrm{AD}$ is expected to increase to 131.5 million. All of these mental disorders and neurodegenerative diseases cause great damage to the physical and mental health of patients.

In spite of its prevalence and high costs for the society, neurological disorders are often not correctly diagnosed and treated. Current drugs and methods used to prevent and manage neurological diseases are very limited (5), and treatments to slow, stop, or reverse the course of the disease constitute a great medical need. From 1998 to 2014, 123 AD drugs entered clinical trials, but only four of them were approved by the FDA, with a failure rate of $97 \%$. Several medicinal plants and/or their active ingredients are widely used in the treatment of CNS diseases, showing high safety and remarkable therapeutic effects $(6,7)$. For example, panax notoginsenoside tablets can effectively treat insomnia and anxiety (8), and ginsenoside Rb1 has been developed as a potential therapeutic drug for $\operatorname{AD}(9,10)$. Thus, it is urgent to explore natural active ingredients as sources of new therapy for neurological diseases.

Radix Polygalae (RP), extensively used as a folk medicine, is derived from the dried root of Polygala tenuifolia Willd. or Polygala sibirica L. Widely used in traditional Asian medicine in China, Japan, and South Korea for a long history, PR is considered as a top-grade herbal medicine that is described to enter the heart and kidney meridian in Shennong's Classic of Materia (Shen Nong Ben Cao Jing) and is also believed to be effective in soothing the nerves, dispelling phlegm, and dissipating edema. Among the chemical composition of RP, triterpenoid saponins, ketones, and oligosaccharide esters are thought to be the basis of RP CNS effects (11). The neuroprotectant properties of RP may result from improvement of cholinergic system and restriction of oxidative stress (free radical scavenging) (12).

To date, there is no systematic review of RP data in the context of neurological conditions and psychotic disorders. This paper reviews phytocompounds, therapeutic effects, and mechanisms of action, aiming to comprehensively summarize the existing research on RP related to the CNS and analyze its preventive potential. It is hoped that this overview will help to explain the results of clinical trials and promote the development of new treatments based on traditional knowledge in the area.

A literature search was conducted using the PubMed database. We searched for studies that were published from January 1, 1998, to December 30, 2020. The search strategy combined the following keywords and corresponding terms in the title and/or abstract: "Radix Polygalae," "central nervous system disorders," and "mental and psychotic disorders."

\section{CHEMICAL COMPOSITION}

The components of RP include saponins, oligosaccharides, ketones, alkaloids, polysaccharides, and flavonoids, and it has pharmacological effects related to sedation, anticonvulsive action, antidepressant action, anti-myocardial ischemic action, and learning and memory enhancement, as shown in Figure $\mathbf{1 .}$ Due to its neuroprotective effects on nerve cells, such as antidepressive effects and learning and memory improvements
$(12,13)$, these extracts and active ingredients are receiving increasing attention from researchers.

\section{Polygala Saponins}

The polygala saponins, as the active ingredients, are rich in the roots and stalks of RP (Figures 1A,B). The total saponin content of $P$. tenuifolia Willd. in the aerial parts (stem and leaf) is up to $2.46 \%$ and that in root is $3.29 \%$. The total saponin content in the stems and leaves of P. sibirica $L$. is 1.50 and $1.61 \%$, respectively, and ginsenosides and saponins are mainly in the roots. However, there are differences in the structure of ginsenosides and polygalasaponin (senegenin): the basic nucleus of the polygala saponin is an oleanolic acid-type pentacyclic triterpenoid, and the two types are the dammaranetype tetracyclic triterpenoid saponin and the oleanolic acidtype pentacyclic triterpenoid saponin, respectively (14), such as the protopanaxadiol saponin $\operatorname{Rb} 1(15,16)$ and the original ginseng triol-type saponin $\operatorname{Rg} 1(17,18)$ (Figures 1I,J). Senegenin (Figure 1C) is treated as the mother nucleus of the polygala saponins and can be linked to different sites, including sugars $(12,17,19,20)$ such as onjisaponin B (Figure 1D) and tenuifolin (Figure 1E), as reported in the previous studies $(21,22)$.

\section{Oligosaccharide Esters}

Polygala oligosaccharide ester is a unique chemical component found in Polygala species and is mainly concentrated in the roots (23). Its mother nucleus is mainly composed of glucose, sucrose, or other trisaccharide (Figure 1F) that are linked to glucose or rhamnose with glycosidic bonds to form oligosaccharides and further combined with organic acid components (acetic acid, benzoic acid, and cinnamic acid) to form an ester, in which the oligosaccharide (no more than five molecular sugars) is glycosidically bonded $(24,25)$. Currently, hundreds of oligosaccharide esters have been isolated from RP, such as tenuifoliose A Q (Supplementary Material 1) and tenuifoliside A E (as shown in Figure 1G). However, 3,6' -disinapoylsucrose (DISS) (Figure 1H) is unique to the genus Polygala $(21,22)$ and Polygala oligosaccharide $(12,17,19,22)$.

\section{Polygalaxanthone}

Polygalactones are a class of phenolic compounds in the form of derivatives, represented by polygalaxanthone III $(21,22,26)$ (Figure 1K), that have diuretic, antibacterial, anticancer, and antidepressant among other biological activities. In addition, a variety of alkaloids were isolated from Polygala: $\mathrm{N}$-formyl halo, 1butoxycarbonyl- $\beta$-carboline, 1 -ethoxycarbonyl- $\beta$-carboline, and 1 -methoxycarbonyl- $\beta$-porphyrin. However, the pharmacological action of alkaloids on the CNS has been reported to be low.

At the same time, less has been reported on chemical modifications of the active natural components to further enhance the effects in the treatment of antipsychotic diseases, which should be the focus of scientific research. Based on existing natural compounds with good activity, chemical modifications further carry out targeted structural transformation, improve binding sites, improve solubility, and improve tissue targeting, which provide excellent prospects for psychotropic drug development. 

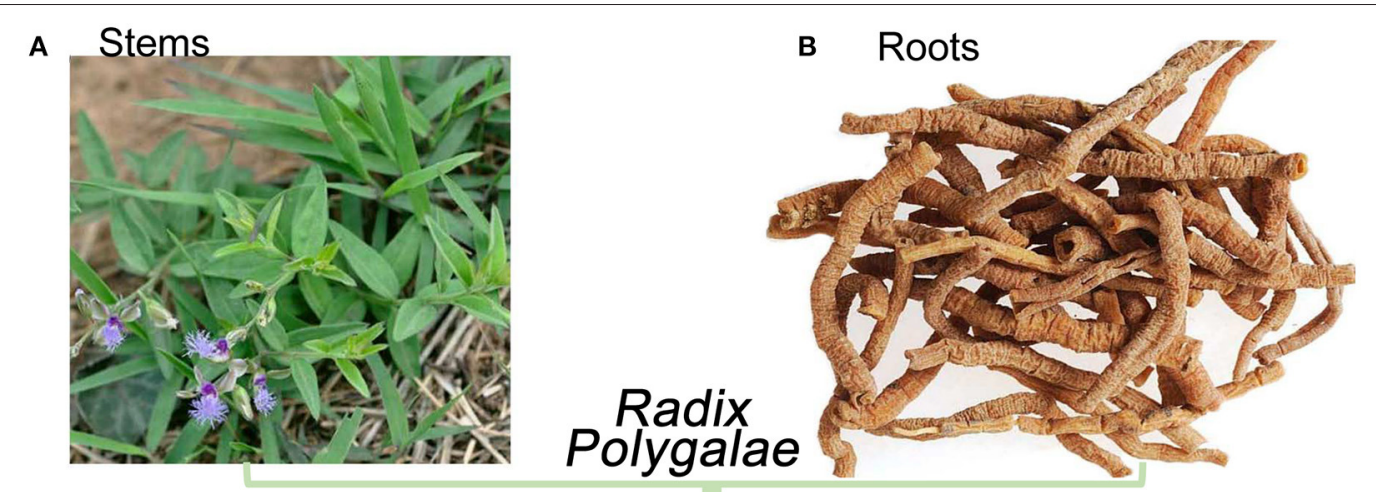

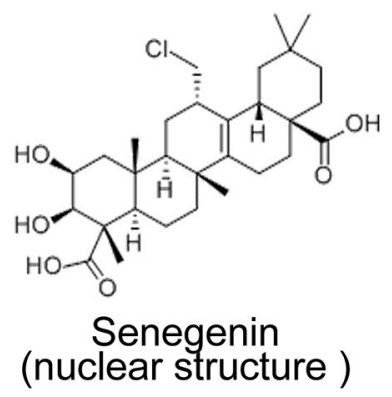

D

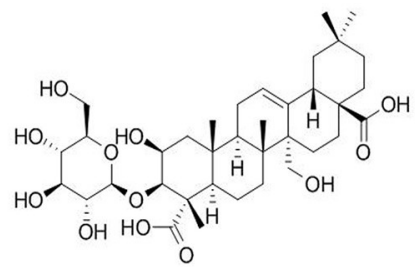

Onjisaponin B
F

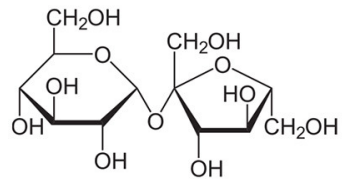

Sucrose (nuclear structure )

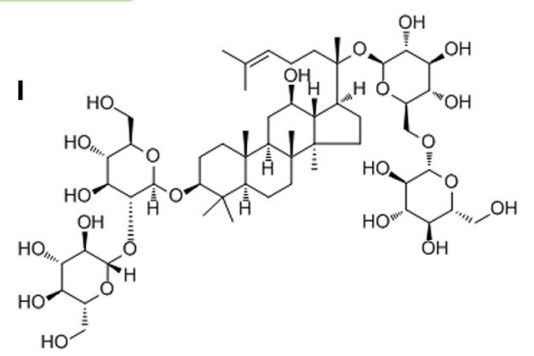

Ginsenoside Rb1

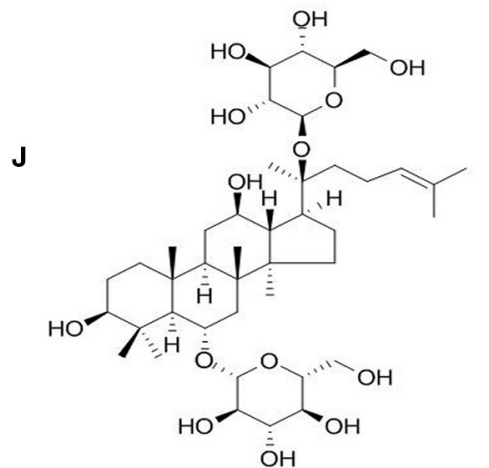
3,6'-disinapoyl sucrose (DISS)<smiles>COc1cc(/C=C/C(=O)OC2C(OC3OC(C)C(O)C(O)C3O)OC(OCCCc3cccc(C)c3)C(O)C2OC2OCC(O)[C@H](O)C2O)ccc1O</smiles>

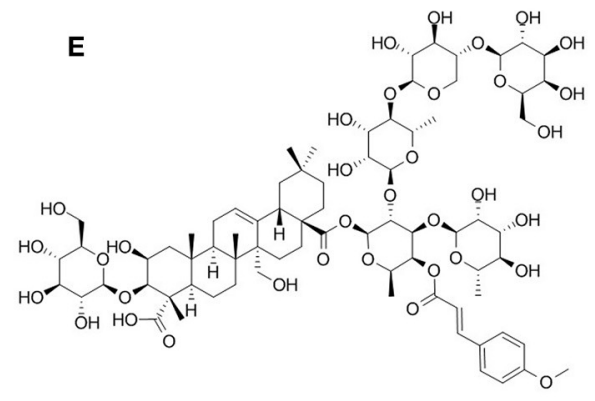

Tenuifolin<smiles>COc1cc(/C=C/C(=O)OCC2OC(OC3(OC(=O)/C=C/c4cc(OC)c(OC)c(OC)c4)OC(CO)C(O)C3O)C(O)C(O)C2O)cc(OC)c1OC</smiles>

Tenuifoliside B<smiles>COc1cc2c(=O)c3c(O)c(C4O[C@H](CO[C@H]5OC[C@H](CO)[C@H]5O)[C@@H](O)[C@H](O)[C@H]4O)c(O)cc3oc2cc1[18OH]</smiles>

Polygalaxanthone III

FIGURE 1 | Sources and main chemical structure of the representative components of Radix Polygalae. (A,B) Stems and roots of RP; (C) senegenin as the mother nuclear structure of polygala saponins; (D) onjisaponin B; (E) tenuifolin; (F) sucrose as the mother nuclear structure of polygala saponins; (G) 3,6 '-disinapoyl sucrose 3,6' (DISS); (H) tenuifoliside B; (I) ginsenoside Rb1; (J) ginsenoside Rb1; (K) polygalaxanthone III. 


\section{BIOLOGY}

\section{Sedative and Anxiolytic Effects}

Recent studies report anxiolytic-like and anticonvulsant effects obtained with the RP extract and/or its active ingredients (2729). Table 1 summarizes the effects in anxiety-like behavior, levels of monoamines, and quality of sleep time by $P$. tenuifolia (a major plant source of RP) root extract, polygalasaponins, and tenuifolin in experimental models. However, the potential mechanisms of its anxiolytic-like and anticonvulsant effects remain unclear.

The extracted polygalasaponins possess evident anxiolytic and sedative-hypnotic activities, with a relatively safe dose range (28). In the open field test, the administration of polygalasaponins (40-160 mg/kg) significantly increased central crossing and the percentage of central/total ambulation and markedly inhibited the number of rearing and defecations. Additionally, increases in the number of head dips in the board hole and the time spent in the open arms of the elevated plus-maze test, prolonged sleep duration, and shortened sleep latency were observed (28).

Tenuifolin administration (40 and $80 \mathrm{mg} / \mathrm{kg}$, p.o.) significantly prolonged total sleep time, increased the amount of nonrapid eye movement and rapid eye movement sleep, and bouts of episodes. Neurochemical correlations include increased c-Fos positive ratios; reduced noradrenaline levels in the locus coeruleus (LC), ventrolateral preoptic area (VLPO), pontomesencephalic tegmental area (PPT), and laterodorsal tegmental area (LDT); elevated GABA levels in the VLPO and LC; and increased acetylcholine (Ach) levels in the LDT and PPT (27). Overall, the data supports the use of $P$. tenuifolia root as anxiolytic and hypno-sedative drug in traditional medicine.

$P$. tenuifolia root extract contains the adenosine $A_{1}$ receptor antagonists 8-cyclopentyl-1,3-dimethylxanthine and alloxazine, which are related to the effect of PTE in preventing cocaineinduced behavioral effects (29).

\section{Antidepressant Effects}

$\mathrm{RP}$ is thought to exert a variety of antidepressant effects. As shown in Table 1, various extracts and purified fractions of RP showed significant antidepressant-like effects in animal models. The mechanism of action includes the following: improving neural cell by reducing serum CORT, ACTH, and $\mathrm{CRH}$ levels; increasing SOD activity; decreasing brain monoamine oxidase (MAO-A and MAO-B) activity and serum malondialdehyde (MDA) levels; promoting autophagy and inhibiting neuroinflammation; regulating the glutamate AMPA receptor, and decreasing GluR1 phosphorylation. The studies were mainly about the four fractions of an ethanol extract as well as the active components DISS and tenuifoliside A (TEA).

The oral administration of RP $(200 \mathrm{mg} / \mathrm{kg})$ showed significant anti-immobility effects on the tail suspension test (TST) and forced swim test (FST), inhibited corticosterone-induced $\mathrm{SH}$ SY5Y cell injury, improved cell viability, and promoted cell proliferation (30). The extracts had antidepressant-like activity via inhibition of triple monoamine reuptake (32). Bioassayguided screening methods showed two bioactive compounds: DISS and TEA $(33,34)$.
Oral administration of $0.1 \mathrm{mg} / \mathrm{kg}$ RP extract decreased behavioral despair in the forced swim and tail suspension tasks, increased hedonic-like behavior in the female urine sniffing test, and decreased the number of failed escapes in the learned helplessness paradigm in male C57Bl/6 mice (31). This study suggested that RP exerted rapid-onset antidepressant effects by regulating the AMPA receptor and decreasing GluR1 phosphorylation at serine-845 in the hippocampus, thus modulating glutamatergic synapses in critical brain circuits of depression. Moreover, Wistar rats were exposed to 6-h restraint stress daily for 28 days, and RP extract ( 0.5 and $1 \mathrm{~g} / \mathrm{kg}$ ) exerted a remarkable antidepressant activity in behavioral despair mice and induced rats, probably by promoting autophagy and inhibiting neuroinflammation (24).

DISS, an oligosaccharide ester component isolated from the roots of $P$. tenuifolia, improved the reward reaction and increased sucrose consumption in rats $(33,34)$. In addition, DISS $(10-$ $20 \mathrm{mg} / \mathrm{kg}$, gavage) remarkably reduced serum CORT, ACTH, and $\mathrm{CRH}$ levels; increased SOD activity in the plasma and brain; decreased brain MAO-A and MAO-B activity in the brain; reduced plasma cortisol levels (34); and downregulated MDA levels in the serum and brain (33), suggesting that the antidepressant-like effects of DISS might be related to modulating the hypothalamic-pituitary-adrenal (HPA) axis and enhance the expression of glucocorticoid and mineralocorticoid receptors in CMS rats $(33,34)$.

\section{Learning and Memory Improvements}

Learning and memory disorders arise from distinct ageassociated processes, and aging animals are often used as a model of memory impairment. As the memory-improving effects of RP have been reported in various animal models, it is more and more commonly used in some Asian countries for this purpose.

As it can be seen in Table 2, multiple extracts and/or the active ingredients of $P$. tenuifolia extract are active in memoryrelated animal models. In a postoperative cognitive dysfunction model in elderly rats having undergone splenectomy, $P$. tenuifolia crude extract (35), a precipitate fraction (PTB) from RP (37), and senegenin can significantly inhibit the mRNA and protein expression levels of several key pro-inflammatory cytokines, reducing tumor necrosis factor- $\alpha$ (TNF- $\alpha$ ), interleukin- $1 \beta$ (IL$1 \beta)$, IL-6, and IL-8 levels, in the hippocampal tissues (41). In addition, a saponin-rich fraction obtained by the purification of $P$. tenuifolia crude extract significantly improved learning and memory in normally aged mice in the Morris water maze (MWM), the step-down passive avoidance tests (35), and the eight-arm radial maze task in rats (37) and in 5xFAD transgenic mice (36). All of these effects may be involved in the regulation of the TLR4/MyD88/NF- $\kappa$ B and TLR4/TRIF/NF- $\mathrm{B}$ signaling pathways.

Reports proved that the crude extract of P. tenuifolia (100 and $200 \mathrm{mg} / \mathrm{kg}$ ) significantly improved impaired spatial memory in aging mice in the MWM and step-down tests, an effect that was related to the disruption of superoxide dismutase (SOD) and catalase (CAT) activities, the inhibition of MAO and acetylcholinesterase (AChE) activities, and the decrease in the levels of MDA in the brain tissue (35) (see Table 2). In addition, 
TABLE 1 | Summarized anxiolytic and antidepressant effects of RP in the nervous system.

\begin{tabular}{|c|c|c|c|c|c|}
\hline Models & Methods & Drug material & Effects & Mechanisms & $\mathbf{R F}$ \\
\hline $\begin{array}{l}\text { Aged mice; } \\
\text { SH-SY5Y cells }\end{array}$ & TST and FST & $\begin{array}{l}\text { Ethanol extracts } \\
\text { Four fractions }\end{array}$ & $\begin{array}{l}\uparrow \text { Anti-immobility-like effects; } \\
\uparrow \text { Cell proliferation; } \downarrow \text { SH-SY5Y injury }\end{array}$ & $\begin{array}{l}\uparrow \text { Cell proliferation; } \\
\text { Antidepressant-like } \\
\text { effects }\end{array}$ & (30) \\
\hline CUMS, mice & $\begin{array}{l}\text { TUNEL, FST, TST, } \\
\text { FUST, and LHP }\end{array}$ & Polygalae extract & $\begin{array}{l}\downarrow \text { Behavioral despair; } \\
\downarrow \text { NMDA neurotoxicity; Hedonic-like } \\
\text { behavior; } \downarrow \text { Number of failed escapes }\end{array}$ & $\begin{array}{l}\uparrow \text { BDNF; } \\
\downarrow \text { GluR1 } \\
\text { phosphorylation; } \\
\uparrow \text { Glutamatergic } \\
\text { synapses }\end{array}$ & (31) \\
\hline CUMS, mice & FST and TST & Extract & $\uparrow$ antidepressant-like activity & $\begin{array}{l}\downarrow \text { Triple monoamine } \\
\text { reuptake }\end{array}$ & $(32)$ \\
\hline $\begin{array}{l}\text { CMS } \\
\text { Rats }\end{array}$ & SPT & DISS & $\begin{array}{l}\uparrow \text { SOD activity; } \downarrow \text { cortisol, MAO-A, } \\
\text { and MAO-B; } \downarrow \text { Lipid peroxidation } \\
\text { and MDA }\end{array}$ & $\begin{array}{l}\text { MAO, HPA axis } \\
\text { Oxidative systems }\end{array}$ & (33) \\
\hline $\begin{array}{l}\text { CRS } \\
\text { Rats }\end{array}$ & SPT, FST, and NSFT & Extract & $\begin{array}{l}\uparrow \text { Antidepressant-like activity; } \uparrow \text { LC3-II } \\
\text { and beclin1; } \uparrow \text { NLRP3, ASC, } \\
\text { and caspase-1; } \\
\uparrow \text { Pro-inflammatory cytokines; } \downarrow \text { the level } \\
\text { of p62; Activated microglia and } \\
\text { impaired astrocyte }\end{array}$ & $\begin{array}{l}\text { AMPK-mTOR pathway } \\
\text { Inhibit } \\
\text { neuroinflammation }\end{array}$ & (24) \\
\hline CMS, rats & SPT, FST, and TST & DISS & $\begin{array}{l}\uparrow \text { Reward reaction; } \\
\uparrow \text { sucrose consumption; } \\
\downarrow \text { Serum CORT, ACTH, and } \mathrm{CRH}\end{array}$ & $\begin{array}{l}\text { HPA axis; } \\
\uparrow \text { Glucocorticoid } \\
\text { receptor; } \\
\uparrow \text { Mineralocorticoid } \\
\text { receptor }\end{array}$ & (34) \\
\hline Mice & EPM & Tenuifolin & $\begin{array}{l}\uparrow \text { total sleep time; } \uparrow \text { bouts of episodes; } \\
\uparrow \text { C-Fos positive ratios; } \downarrow \text { NA; } \\
\uparrow \text { GABA, Ach }\end{array}$ & $\begin{array}{l}\text { CREB-BDNF; } \\
\text { ERK1/2 and CaMKII }\end{array}$ & $(27)$ \\
\hline Mice & $\begin{array}{l}\text { EPM, OFT, and } \\
\text { hypnosis tests }\end{array}$ & Saponins & $\begin{array}{l}\uparrow \text { Central crossing counts; } \uparrow \\
\text { central/total ambulation; } \downarrow \text { Number of } \\
\text { rearings; } \uparrow \text { Head-dips; } \uparrow \text { sleep duration; } \\
\downarrow \text { sleep latency }\end{array}$ & $\begin{array}{l}\text { Evident anxiolytic and } \\
\text { sedative-hypnotic } \\
\text { activities }\end{array}$ & $(28)$ \\
\hline $\begin{array}{l}\text { Cocaine; } \\
\text { Mice }\end{array}$ & $\begin{array}{l}\text { Locomotor activity and } \\
\text { CPP }\end{array}$ & Extracts & $\begin{array}{l}\downarrow \text { Hyperactivity; } \\
\downarrow \text { Locomotor activity }\end{array}$ & $\begin{array}{l}\uparrow \text { Adenosine } A_{2 A} \\
\text { receptor }\end{array}$ & $(29)$ \\
\hline
\end{tabular}

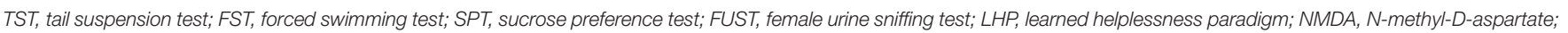

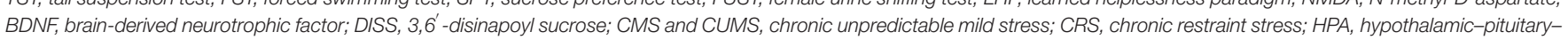

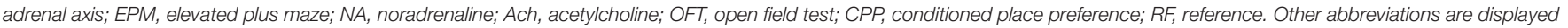
in the literature.

the oral administration of PTB of $P$. tenuifolia root and a saponinrich fraction obtained from PTB (100 and $200 \mathrm{mg} / \mathrm{kg}$ ) decreased the number of total errors of working memory as evaluated in the rat eight-arm radial maze tasks (37). Additionally, $P$. tenuifolia extracts had beneficial effects on the scopolamineinduced dysfunction of the cholinergic system-induced memory impairment in the radial maze performance (37).

The oral administration of RP $(3,6$, and $12 \mathrm{mg} / \mathrm{kg} ; 14$ days) reversed scopolamine-induced amnesic effects such as increased escape latency time, decreased number of crossings, and shortened time spent in the target quadrant. RP significantly improved the cholinergic system reactivity by decreasing AChE activity, increasing choline acetyltransferase (ChAT) activity, and elevating levels of $\mathrm{ACh}$, which ameliorated neuroinflammation and inhibited oxidative stress in mice (38).

Finally, senegenin, an active component of extracts from $P$. tenuifolia root, significantly inhibited the mRNA and protein expression of several key pro-inflammatory cytokines by downregulating the inflammation signaling pathways dependent on TLR4/MyD88/NF- $\kappa \mathrm{B}$ and TLR4/TRIF/NF- $\kappa \mathrm{B}$ and by reducing TNF- $\alpha$, IL-1 $\beta$, IL-6, and IL- 8 levels in hippocampal tissues in the postoperative cognitive dysfunction model of elderly rats having undergone splenectomy (41). These results suggest that RP might exert a significant neuroprotective effect by improving learning and memory, driven in part by the modulation of cholinergic activity and neuroinflammation.

\section{Alzheimer's Disease}

$\mathrm{AD}$ is a progressive degenerative disease of the CNS that involves impaired language and memory function. The accumulation of the amyloid $\beta$-protein $(A \beta)$ is a pivotal pathological factor in AD. Most studies and searches for effective drugs have been conducted from the perspectives of cholinergic system decline, neuronal apoptosis, oxidative stress, and neuro-inflammation induced by the disease.

As mentioned, RP has been widely used in neurodegenerative diseases in traditional Chinese medicine. As summarized at Table 2, our review shows that RP can alleviate pathological changes in mice, reduce neurofibrillary tangles and amyloid fibrosis senile plaques in the hippocampus and cerebral 
TABLE 2 | Summarized effects of RP on improving learning, memory, and cognitive function in the nervous system.

\begin{tabular}{|c|c|c|c|c|c|}
\hline Models & Methods & Drug material & Effects & Mechanisms & RF \\
\hline Aged mice & MWM SPAT & Crude extract & $\begin{array}{l}\uparrow \text { SOD }-2 ; \uparrow \text { Impaired spatial memory; } \\
\uparrow \text { SOD and CAT activities; } \downarrow \text { MAO and } \\
\text { AChE activities }\end{array}$ & $\begin{array}{l}\downarrow \mathrm{MAO} \text { and } \mathrm{AChE} \\
\text { Antioxidant properties }\end{array}$ & $(35)$ \\
\hline $\begin{array}{l}\text { Neurons } \\
\mathrm{A} \beta \text { and } \mathrm{H}_{2} \mathrm{O}_{2} \\
\mathrm{AD} \text { model mice }\end{array}$ & $\begin{array}{l}\text { NOR; TUNEL; DCF-DA } \\
\text { assay }\end{array}$ & PSM-04 & $\begin{array}{l}\downarrow \text { Cognitive impairments; } \downarrow \text { Amyloid } \\
\text { plaques and gliosis; } \\
\downarrow \text { Cognitive impairment }\end{array}$ & $\begin{array}{l}\downarrow \text { Oxidative stress } \\
\downarrow \text { Apoptosis }\end{array}$ & (36) \\
\hline $\begin{array}{l}\text { Rats } \\
\text { Scopolamine }\end{array}$ & ERM; RMP & $\begin{array}{l}\text { Extracts, PTB PTBM, } \\
\text { and SNPA }\end{array}$ & $\begin{array}{l}\downarrow \text { number of total errors; } \\
\uparrow \text { Short-term memory }\end{array}$ & $\uparrow$ memory & (37) \\
\hline $\begin{array}{l}\text { Mice } \\
\text { Scopolamine }\end{array}$ & MWM & PA & $\begin{array}{l}\uparrow \text { Escape latency time; } \uparrow \text { SOD, } \\
\downarrow \text { MDA, glutathione; } \uparrow \text { Number } \\
\text { of crossings }\end{array}$ & $\begin{array}{l}\downarrow \text { AChE activity; } \\
\uparrow \text { ChAT; Ach; } \\
\downarrow \text { Neuroinflammation }\end{array}$ & (38) \\
\hline $\begin{array}{l}\text { SH-SY5Y; } \\
\text { Mice; rats; } \\
\text { Primary neurons }\end{array}$ & MWM and SPAT & Triterpenoid saponins & $\begin{array}{l}\uparrow \text { Synaptic transmission; } \uparrow \text { Cognition and } \\
\text { memory activity; } \uparrow \text { BDNF, NGF; } \downarrow \text { toxicity; } \\
\uparrow \text { ChAT }\end{array}$ & $\begin{array}{l}\text { MAPK; } \\
\text { CREB-BDNF; } \\
\text { ERK1/2 and CaMKII }\end{array}$ & (39) \\
\hline $\begin{array}{l}\text { Mice } \\
\text { A } 325-35\end{array}$ & MWM and SPAT & $\begin{array}{l}\text { Tenuifolin and } \\
\text { fallaxsaponin A }\end{array}$ & $\begin{array}{l}\downarrow \text { Cognitive deficits; } \downarrow \text { apoptosis in } \\
\text { PC12 cells }\end{array}$ & $\uparrow$ COGNITIVE function & $(40)$ \\
\hline $\begin{array}{l}\text { POCD rats; } \\
\text { Splenectomy }\end{array}$ & MWM & Senegenin & $\begin{array}{l}\downarrow \text { TLR4 } \downarrow \text { Cognitive impairment; } \downarrow \text { TNF- } \alpha \text {, } \\
\text { IL-1 } \beta, \text { IL-6, and IL-8; } \downarrow \text { Key } \\
\text { pro-inflammatory cytokines; }\end{array}$ & $\begin{array}{l}\downarrow T L R 4 / T R I F / N F-\kappa B ; \\
\downarrow T L R 4 / M y D 88 / N F-\kappa B ; \\
\downarrow N F-\kappa B \\
\text { phosphorylation }\end{array}$ & $(41)$ \\
\hline $\begin{array}{l}\text { APP695, } \\
\text { SPA4CT }\end{array}$ & In vitro SH-SY5Y & Tenuigenin & $\begin{array}{l}\downarrow \mathrm{A} \beta \text { and } \mathrm{C} 99 ; \\
\downarrow \mathrm{BACE} 1 \text { proteolytic activities }\end{array}$ & $\begin{array}{l}\downarrow \text { BACE1; } \\
\downarrow \text { Secretion of } A \beta\end{array}$ & $(42)$ \\
\hline $\begin{array}{l}\text { Potassium cyanide } \\
\text { scopolamine } \\
\text { impairment rats }\end{array}$ & SPAT & Tenuifoliside B & $\begin{array}{l}\uparrow \text { Cerebral protective effect; } \\
\uparrow \text { Oxotremorine-induced tremors; } \\
\downarrow \text { Impairment of performance }\end{array}$ & $\uparrow$ Cholinergic system & $(43)$ \\
\hline
\end{tabular}

MWM, Morris water maze; SPAT, step-down passive avoidance tests; CAT, catalase; NOR, novel object recognition; SOD-2, superoxide dismutase-2; ERM, eight-arm radial maze; PA,

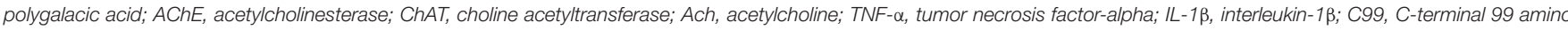
acids of APP; MAPK, mitogen-activated protein kinase.

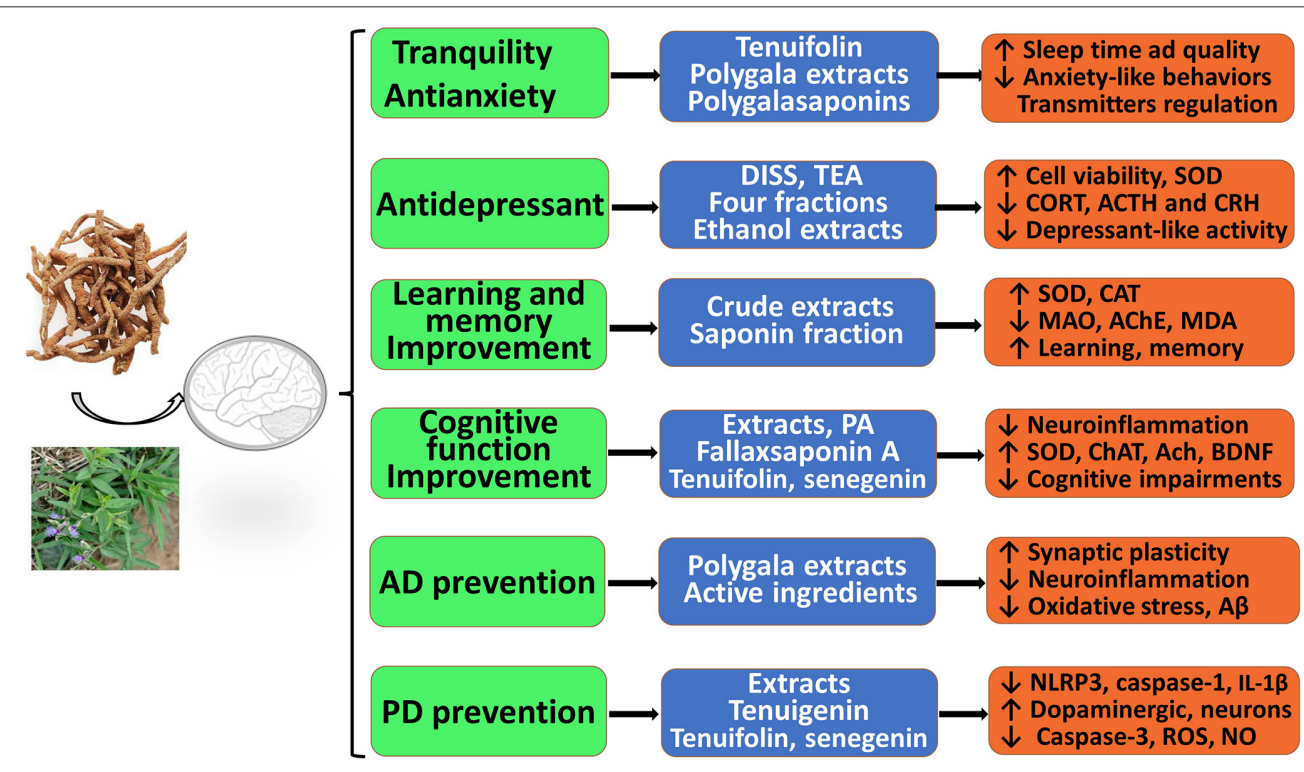

FIGURE 2 | Therapeutic and preventive actions of RP against central nervous system (CNS) neurological and psychotic diseases in vitro and in vivo. It possesses significant pharmacological activities and protective effects with administration of therapeutic material basis, including RP extracts, multiple effective fractions, and single components.

cortex, and promote the regeneration of new neurons in the dentate granule cells $(36,39,40,42)$. The authors suggest that these effects may be associated with RP antioxidative, anti-inflammatory, and anti-apoptotic effects; HPA axis regulation; increase in monoamine neurotransmitter release; BDNF and NGF expression; neuronal synaptic plasticity; and 
TABLE 3 | Neuroprotective mechanisms of Radix Polygalae against oxidation stress, inflammatory, and apoptosis in the nervous system.

\begin{tabular}{|c|c|c|c|c|c|}
\hline Models & Methods & Drug material & Effects & Mechanisms & RF \\
\hline $\begin{array}{l}\text { Glu } \\
\text { sY5Y cells }\end{array}$ & In vitro, inhibitor U0126 & $\begin{array}{l}\text { DISS } \\
\text { TEA }\end{array}$ & $\begin{array}{l}\downarrow \text { cell viability; } \uparrow \text { CRTC1 and BDNF; } \\
\downarrow \text { NOS hyperactivation; } \uparrow \\
\text { CREB phosphorylation }\end{array}$ & $\begin{array}{l}\text { PI3K; } \\
\text { MAPK/ERK1/2; } \\
\text { CREB-BDNF }\end{array}$ & $(48)$ \\
\hline $\begin{array}{l}\text { Rats } \\
\text { Brain slices }\end{array}$ & In vitro & Tenuifoliside & $\begin{array}{l}\uparrow \text { Slope of fEPSPs; } \downarrow \text { Paired-pulse } \\
\text { facilitation ratio; } \uparrow \text { Frequency } \\
\text { and amplitude }\end{array}$ & $\begin{array}{l}\uparrow \text { Synaptic; } \\
\downarrow \text { Intracellular calcium }\end{array}$ & (49) \\
\hline Rat cortical neurons & In vitro & Senegenin & $\begin{array}{l}\uparrow \text { Akt phosphorylation; } \uparrow \text { Neuronal } \\
\text { outgrowth and survival }\end{array}$ & PI3K/Akt & $(50)$ \\
\hline $\begin{array}{l}\text { Rat } \\
\text { Glioma C6 cells }\end{array}$ & $\begin{array}{l}\text { In vitro; inhibitors } \\
\text { U0126 and LY294002 }\end{array}$ & TEA & $\begin{array}{l}\downarrow \text { apoptosis; } \uparrow \text { cell viability and BDNF; } \\
\uparrow \text { ERK and Akt phosphorylation }\end{array}$ & $\begin{array}{l}\text { BDNF/TrkB; } \\
\text { ERK/PI3K-CREB }\end{array}$ & $(51)$ \\
\hline $\begin{array}{l}\mathrm{H}_{2} \mathrm{O}_{2} \\
\text { Glutamate, } \\
\text { SY5Ycell }\end{array}$ & $\begin{array}{l}\text { In vitro; inhibitors } \\
\text { U0126, KN93, or } \\
\text { K252a }\end{array}$ & DISS & $\begin{array}{l}\uparrow \mathrm{BDNF} ; \uparrow \text { cell viability; } \\
\uparrow \mathrm{CREB} \text { phosphorylation }\end{array}$ & $\begin{array}{l}\text { CREB-BDNF; } \\
\text { ERK1/2 and CaMKII }\end{array}$ & $(52)$ \\
\hline Rat neurons & In vitro & Root extract & $\uparrow$ proliferation; $\uparrow$ Neurite outgrowth & Neurogenesis & $(53)$ \\
\hline Rat neurons & In vitro; NMDA & Extract & $\begin{array}{l}\downarrow\left(\mathrm{Ca}^{2+}\right) \mid \text { and } \mathrm{ROS} ; \downarrow \text { Cell death and } \\
\text { glutamate release }\end{array}$ & $\begin{array}{l}\downarrow \text { Oxidation stress; } \\
\downarrow \text { apoptosis }\end{array}$ & $(54)$ \\
\hline $\begin{array}{l}\text { LPS } \\
\text { astrocytes }\end{array}$ & In vitro & DISS and TEA & $\downarrow$ TNF- $\alpha$ and IL-1 $\beta$ & $\begin{array}{l}\text { Anti-inflammatory } \\
\text { activity }\end{array}$ & $(55)$ \\
\hline $\begin{array}{l}\text { LPS, } \\
\text { Macrophages, } \\
\text { RAW264.7 cells }\end{array}$ & In vitro & TEA & $\begin{array}{l}\downarrow \mathrm{TNF}-\alpha \text { and IL-1 } \beta ; \downarrow \text { NO, iNOS, PGE2, } \\
\text { and COX-2; } \downarrow \text { Pro-inflammatory cytokines }\end{array}$ & $\begin{array}{l}\downarrow \text { p-JNK; } \\
\downarrow \text { NF-kB; } \\
\downarrow \text { MAPK pathways }\end{array}$ & $(56)$ \\
\hline $\begin{array}{l}\text { LPS, } \\
\text { RAW } 264.7 \text { cells }\end{array}$ & In vitro & Tenuigenin & $\begin{array}{l}\downarrow \text { JNK } 1 / 2, \text { ERK } 1 / 2 \text {, and p38; } \\
\downarrow \text { IкB } \alpha \text { phosphorylation; } \downarrow \text { PGE2, NO, } \\
\text { iNOS, and COX-2 }\end{array}$ & $\begin{array}{l}\text { MAPK, NF-кB, } \\
\text { anti-inflammatory } \\
\text { Nrf2/HO-1, and } \\
\text { anti-oxidation }\end{array}$ & $(57)$ \\
\hline $\begin{array}{l}\text { MPTP, } \\
\text { Mice, } \\
\text { BV2 cells }\end{array}$ & In vitro & Water extracts & $\begin{array}{l}\uparrow \text { Striatal } \\
\text { dopaminergic levels; dopaminergic neuron } \\
\uparrow \text { Dopaminergic neuron; } \downarrow \text { ROS, } \\
\text { caspase- } 1 \text {, and IL-1 } 1 \beta \text {; }\end{array}$ & $\begin{array}{l}\downarrow \text { NLRP3 } \\
\text { inflammasome } \\
\text { activation }\end{array}$ & $(45)$ \\
\hline $\begin{array}{l}\text { 6-OHDA, } \\
\text { PC12 cells; } \\
\text { PD mice }\end{array}$ & In vitro and in vivo & Polygalae extracts & $\begin{array}{l}\downarrow \text { ROS and NO } \downarrow \text { cell damage and toxicity; } \\
\downarrow \text { Caspase-3 }\end{array}$ & $\begin{array}{l}\text { Anti-oxidant and } \\
\text { anti-apoptotic activities }\end{array}$ & $(46)$ \\
\hline $\begin{array}{l}\text { LPS, } \\
\text { BV2 cells }\end{array}$ & In vitro & Water extract & $\begin{array}{l}\downarrow N O \text { and PGE2; } \downarrow \text { iNOS } \\
\text { and COX-2; dopaminergic neuron } \downarrow \\
\text { Pro-inflammatory cytokines }\end{array}$ & $\begin{array}{l}\downarrow \text { NF-кB; } \\
\downarrow \text { IkappaB- } \alpha ; \\
\downarrow \text { TLR4 and Myd-88 }\end{array}$ & $(58)$ \\
\hline
\end{tabular}

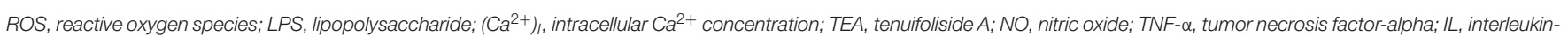

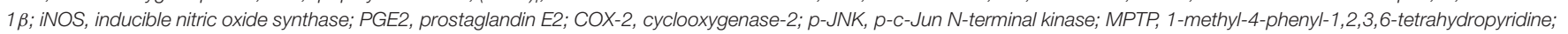
6-OHDA, 6-hydroxydopamine; IkB- $\alpha$, IkappaB- $\alpha$.

nerve cell proliferation. In addition, RP extracts and its active ingredients (tenuifolin and fallaxsaponin $A$ ) may decrease $A \beta$ secretion via BACE1 (beta-secretase) inhibition.

PSM-04, an extract of RP, exhibited significant neuroprotective effects against neurotoxicity induced by Lglutamate or oligomeric $\mathrm{A} \beta$, decreased oxidative stress induced by $\mathrm{H}_{2} \mathrm{O}_{2}$, and decreased apoptotic cell death induced by oligomeric $\mathrm{A} \beta$ in primary cortical neurons (36); in addition, PSM-04 significantly alleviated cognitive impairments in 5xFAD transgenic mice by increasing superoxide dismutase-2 (SOD-2) protein levels, alleviating cognitive impairment, and decreasing amyloid plaque deposition (36).

Tenuifoliside $\mathrm{B}$ showed cerebral protective effects against potassium cyanide-induced anoxia in mice and had an ameliorative effect on scopolamine-induced impairments in the passive avoidance task in rats as well as an ameliorative effect on the reduction in cholinergic function on rat models induced by $A \beta$ (43). Studies on the mechanism of action found that tenuifolin $B$ could inhibit secretion of $A \beta$ in neuroblastoma cells stably transfected with two amyloid precursor protein (APP) constructs: the APP695 cDNA (SH-SY5Y APP695) and the Cterminal 99 amino acid residues of APP plus the signal peptide (SH-SY5Y SPA4CT). Tenuigenin inhibited the secretion of $A \beta$ and the C-terminal 99 amino acids of APP (C99) in SH-SY5Y APP695 cells, but did not change the A $\beta$ and C99 levels in SH-SY5Y SPA4CT cells. Fluorescence resonance energy transfer (FRET) assays showed that tenuigenin inhibited the proteolytic activities of BACE1 on its substrate in vitro (42).

Furthermore, tenuifolin, which is isolated from $P$. tenuifolia roots, showed neuroprotective effects in $\mathrm{A} \beta_{25-35}$ damageinduced PC12 cells in vitro and significantly alleviated cognitive deficits induced by the intrahippocampal injection of $\mathrm{A} \beta_{25-35}$ in mice and APP/PS1 transgenic AD mice model. Its extracts and active ingredients can reduce cell apoptosis by ameliorating 
neuro-inflammation and oxidative stress and can inhibit cell toxicity by regulating BDNF expression, by upstream ERK1/2 pathway, CaMKII activation, and cyclic AMP-responsive element-binding protein (CREB)-mediated BDNF transcription $(40,44)$.

Taken together, these results suggest that more studies are needed in the context of RP products as anti-AD medication.

\section{Parkinson's Disease}

Based on the reported biological and pharmacological activities of $P$. tenuifolia, it can be argued whether it could be useful in the prevention and/or treatment of PD that share with $\mathrm{AD}$ aspects such as neuroinflammation. In fact, it was shown in in vitro and in vivo $\mathrm{PD}$ models of the BV2 microglia cells and the MPTPinduced mice model that tenuigenin significantly increased striatal dopaminergic levels and improved motor impairment induced by MPTP, ameliorated the degeneration of dopaminergic neurons, and inhibited NLRP3 inflammasome activation in the substantia nigra (45). Tenuigenin reduced the production of intracellular reactive oxygen species (ROS), the subsequent caspase- 1 cleavage, and IL- $1 \beta$ secretion in BV2 microglia cells and attenuated microglia activation induced by lipopolysaccharide (LPS) via suppressing NLRP3 inflammasome (45).

$\mathrm{PR}$ extracts have protective effects on dopaminergic neurons via their antioxidant and anti-apoptotic activities (46). PR extracts inhibited 6-OHDA-induced PC12 cell damage, alleviated caspase- 3 activity and the production of ROS and NO, and protected mesencephalic dopaminergic neurons from MPP (+)induced toxicity. It also protected dopaminergic neurons and fibers from MPTP-induced toxicity in the substantia nigra pars compacta (SNpc) and TH-IR fibers in the striatum (ST) (47). These results suggest that RP extracts and tenuigenin may be useful in $\mathrm{PD}$ therapy by counteracting the inflammatory response, oxidative stress, and associated apoptosis.

As described above, RP extracts, multiple fractions, and various effective components have significant neuroprotective effects against CNS neurological and psychotic diseases in vitro and in vivo. As shown in Figure 2, these extracts, active fractions, and active ingredients, including saponins, ketones, oligosaccharides, and alkaloids, have significant pharmacological activities and protective effects against anxiety, depression, cognitive decline, $\mathrm{AD}$, and $\mathrm{PD}$, which suggests that $\mathrm{RP}$ may provide effective tools to combat $\mathrm{AD}, \mathrm{PD}$, depression, and other neurological conditions or disorders. Thus, RP has been attracting more attention from researchers. First, RP extracts, polygalasaponins and tenuifolin, may significantly alleviate anxiety-like behavior, decrease locomotor activity, regulate levels of monoamine neurotransmitters, and improve sleep time and quality; thus, RP has evident tranquility and anti-anxiety effects. However, the potential mechanisms of anxiolytic-like and anticonvulsant effects have been less frequently reported and remain unclear. Second, the various PR extracts, purified fractions, and several active ingredients (DISS, TEA, etc.) may exert obvious antidepressant effects by inhibiting depressionlike behaviors, improving neural cell viability and proliferation, reducing oxidation and apoptosis, and modulating glutamatergic synapses and the HPA axis. Third, RP extracts and their active ingredients (polygalacic acid, tenuifoliside $B$, tenuifolin, fallax saponin $\mathrm{A}$, and senegenin) may improve learning, memory, and cognitive functions; alleviate cognitive impairments; ameliorate neuroinflammation; inhibit oxidative stress; and reduce $A \beta$ secretion and neuronal apoptosis. These findings show the excellent prospects of RP for treating AD. In addition, RP shows promising clinical use for PD therapy.

\section{NEUROPROTECTIVE MECHANISMS}

\section{Neuronal Synaptic Plasticity and Proliferation}

It is well-known that neuron density and function, neurotransmitter levels, and BDNF expression levels are decreased in $\mathrm{AD}$ patients, mostly replicated in animals subjected to experimental models of depression. The expression of BDNF has also been implicated in the effect of many neurological disorders, which is also involved in the expression of neuronal plasticity genes, so it is now also believed that neurodegenerative diseases are frequently associated with a loss of synapses and neurons (6). P. tenuifolia root extracts and their active ingredients proved to be neuroprotective against psychotic or neurodegenerative disease models by regulating the HPA axis, regulating neurotransmitter release, increasing BDNF and NGF expression, improving neuronal synaptic plasticity, and promoting nerve cell proliferation (Table 3 ).

DISS and tenuifoliside (A, B, and C), two natural oligosaccharide esters from $P$. tenuifolia roots, improved neuronal synaptic plasticity, promoted nerve cell proliferation, and showed neuroprotective effects via inhibiting glucocorticoid-induced NOS hyper-activation, upregulating the phosphorylation of CREB, and increasing the expression of BDNF in corticosterone-induced SH-SY5Y cells (19). Senegenin was also found to promote neurite outgrowth and neuronal survival in primary cultured rat cortical neurons $(50,59)$. The studies showed that the effects may be related to stimulating different upstream pathways of CREB via the MAPK/ERK1/2, phosphoinositide-3 kinase (PI3K), and CREB-BDNF pathways, which was demonstrated in vitro (19). The neurotrophic effects of senegenin were significantly inhibited by the $A_{2 A}$ receptor antagonist ZM241385 and the specific PI3K inhibitor LY294002, suggesting that senegenin may be involved in the PI3K/Akt signaling pathway $(50,59)$.

Neuroprotective and anti-apoptotic effects were shown for TEA. TEA increased the levels of phospho-ERK and phosphoAkt, improved CREB phosphorylation at Ser133, and, thus, enhanced the release of BDNF in rat glioma cells C6. Inversely, these effects were blocked by ERK and PI3K inhibitors (U0126 and LY294002, respectively). Therefore, it was speculated that the neuroprotective effects of TEA in C6 glioma cells might be mediated by the BDNF/TrkB-ERK/PI3K-CREB signaling pathway (51).

RP root extract on proliferation of neural stem cells in the hippocampal CA1 region (2 $\mathrm{mg} / \mathrm{kg} /$ day, 14 intraperitoneal injections) could increase the incorporation of bromodeoxyuridine (BrdU) into cells in the hippocampal CA1 


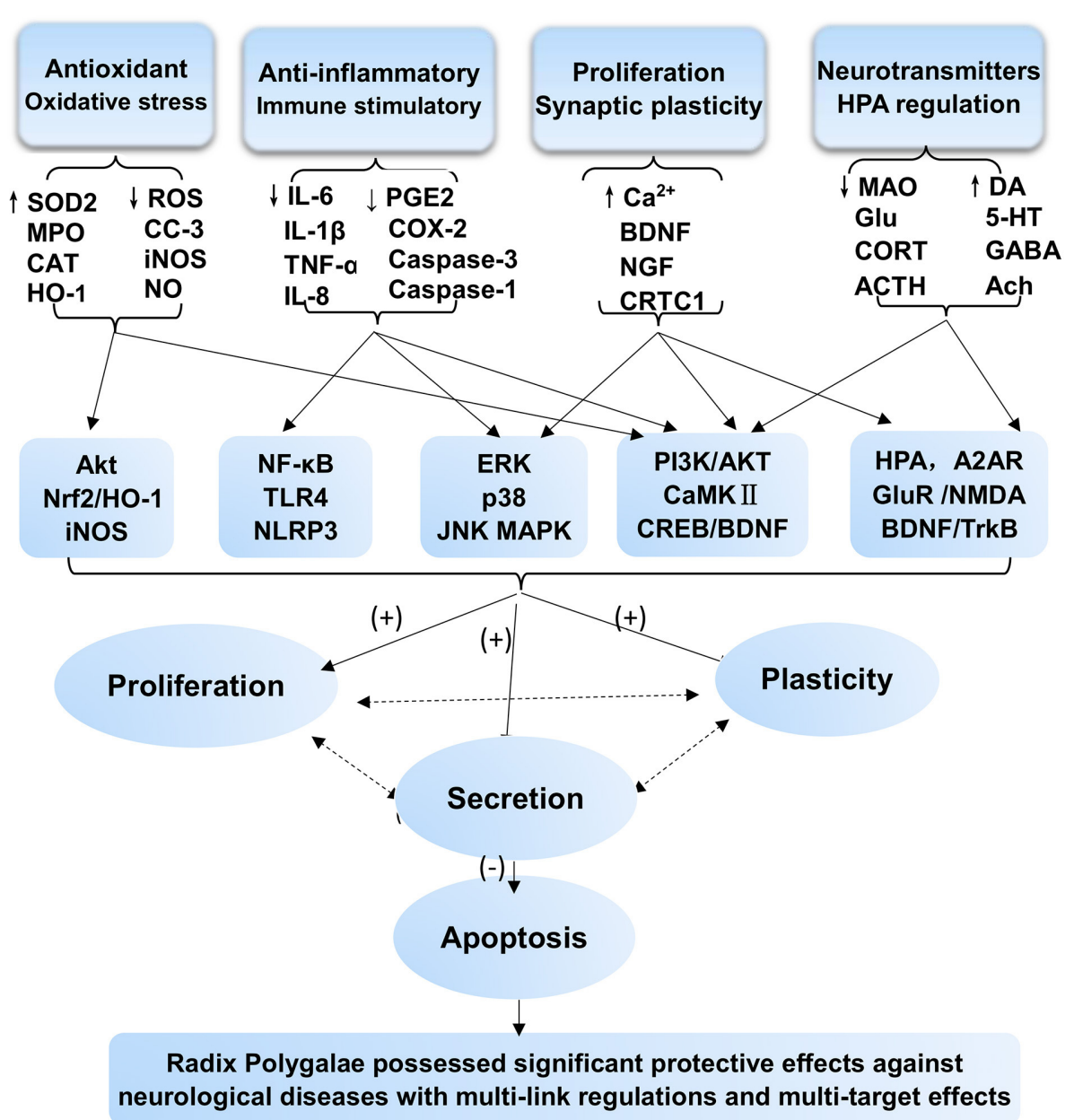

FIGURE 3 | Protective effects and mechanism network analysis of RP against CNS neurological and psychotic diseases in vitro and in vivo with multiple links across regulatory mechanisms and multitarget effects. Minus sign (-) stands for downregulation or inhibition; plus sign (+) stands for upregulation or activation; question mark (?) stands for uncertainty or no determination.

region and promote the proliferation of neural stem cells in the rat hippocampus, an effect potentially beneficial to conditions like insomnia, neurosis, and dementia (53).

Tenuifoliside enhanced basic synaptic transmission by stimulating presynaptic intracellular calcium as shown by in vitro field potential electrophysiology and whole-cell patch clamp techniques (49). Tenuifoliside significantly enhanced the slope of field excitatory postsynaptic potentials (fEPSPs), reduced the ratio of paired-pulse facilitation, increased the frequency of spontaneous excitatory postsynaptic currents (mEPSCs), and increased their amplitude; these effects were blocked by chelating intracellular calcium with BAPTA-AM (49).

\section{Antioxidative Effects}

RP extracts and their active ingredients show obvious neuroprotective effects against oxidative stress and apoptosis (60), while also improving nerve growth, neuronal plasticity, neurotransmitter reuptake, and neurogenesis.

Two oligosaccharide esters from RP, tenuifoliside and DISS, were shown to inhibit NOS hyper-activation, toxicity, and apoptosis in glutamate- and $\mathrm{H}_{2} \mathrm{O}_{2}$-damaged SH-SY5Y, ameliorating neuron viability in a dose-dependent manner. Both esters increased BDNF expression and CREB phosphorylation via the regulation of upstream MAPK/ERK1/2 and PI3K in the CREB-BDNF pathway (48). In in vivo rat models (Table 3), DISS showed distinct neuroprotective effects via the modulation of BDNF and CREB expression, and CREB-BDNF regulation was associated with the upstream activation of ERK1/2 and CaMKII, verified by the inhibitors (H89, LY294002, U0126, KN93, and K252a) (52).

In primarily cultured rat cerebellar granule neurons, RP extracts inhibited NMDA (1 mM)-induced neuronal cell death, inhibited glutamate release into the medium, inhibited the elevation of intracellular $\mathrm{Ca}^{2+}$ concentration $\left[\left(\mathrm{Ca}^{2+}\right) \mathrm{i}\right]$ (49), and inhibited the generation of ROS (54). It also inhibited 6-OHDA-induced PC12 cell damage and increased caspase- 3 activity and the production of ROS and NO (46). In LPS-induced RAW 264.7 macrophages, RP dramatically upregulated heme oxygenase (HO)-1 and Nrf2 expressions, which were partially reversed by HO-1-siRNA 
and HO-1 inhibitors (57), suggesting that RP extracts have significant neuroprotective actions via its antioxidant and anti-apoptotic activities.

\section{Anti-inflammatory Effect}

There is an increasing evidence suggesting that inflammation plays a crucial role in the development of psychotic diseases (61) (Table 3). Inflammation is triggered by various internal and external stress stimuli, which in turn can cause abnormal changes in the normal physiological functions of serotonin (5-HT) and the HPA axis, eventually leading to anxiety and depression. Studies have shown that $P$. tenuifolia root extract has obvious anti-inflammatory activity, which can improve cytokine levels, regulate inflammation-related pathways, and, thus, may be useful for treating psychosis (38, 45, 56, 58).

In primary cultures of mouse astrocytes, the RP aqueous extract inhibits TNF- $\alpha$ secretion and decreases IL- $1 \beta$ secretion. These results suggest that PTAE has anti-inflammatory activity in the CNS, assisting to counteract the neuroinflammation that accompanies various pathological conditions $(55,60)$.

Increasing evidence suggests that tenuigenin possesses antioxidative and anti-inflammatory activities (Table 3). Tenuigenin dramatically reduces prostaglandin E2 and NO production (57) and suppresses the production of pro-inflammatory cytokines such as TNF- $\alpha$ and IL-1 $\beta$ in LPS-induced RAW264.7 macrophages (56), which was related to decreased iNOS and COX-2 gene expression. Furthermore, PR extracts and TEA inhibited JNK1/2, ERK1/2, p38, and NF-кB (p65) phosphorylation and blocked $\mathrm{I} \kappa \mathrm{B} \alpha$ phosphorylation and degradation. Together, tenuigenin showed obvious antiinflammatory activity via the inhibition of the NF- $\kappa$ B and MAPK pathways $(56,57)$. Tenuigenin significantly increased striatal dopaminergic levels, improved motor impairment induced by MPTP, ameliorated the degeneration of dopaminergic neurons, and inhibited NLRP3 inflammasome activation in MPTP mice (45). Additionally, tenuigenin obviously reduced intracellular ROS production; suppressed NLRP3 inflammasome activation, subsequent caspase- 1 cleavage, and IL-1 $\beta$ secretion; and attenuated microglia activation via suppressing the NLRP3 inflammasome in BV2 microglia cells (45). All the results suggest that the neuroprotective effects of tenuigenin are associated with the inhibition of NLRP3 inflammasome activation (45).

\section{REFERENCES}

1. Charlson F, van Ommeren M, Flaxman A, Cornett J, Whiteford H, Saxena S. New WHO prevalence estimates of mental disorders in conflict settings: a systematic review and metaanalysis. Lancet. (2019) 394:240-8. doi: 10.1016/S0140-6736(19)3 0934-1

2. Baxter AJ, Scott KM, Vos T, Whiteford HA. Global prevalence of anxiety disorders: a systematic review and meta-regression. Psychol Med. (2013) 43:897-910. doi: 10.1017/S003329171200147X

3. Evans-Lacko S, Aguilar-Gaxiola S, Al-Hamzawi A, Alonso J, Benjet C, Bruffaerts $\mathrm{R}$, et al. Socio-economic variations in the mental health

\section{CONCLUSIONS}

$\mathrm{RP}$, as a medicinal herb, is the dried root of $P$. tenuifolia Willd. or $P$. sibirica $L$. and has been widely used as an expectorant, tonic, tranquilizer, and antipsychotic agent. Its pharmacological effects are well-documented in extracts, extract fractions, and isolated compounds affecting various aspects of neurodegenerative disorders, including $\mathrm{AD}$ and $\mathrm{PD}$, as well as neuropsychiatric disorders. This review summarized that RP has prominent benefits for the CNS. The underlying mechanisms and the therapeutic material basis are shown in Figures 2, 3. Our analysis indicates that the main mechanisms involved include the following: antioxidant effects and associated apoptosis; antiinflammatory effects and related apoptosis; and neurological proliferation, regeneration differentiation, and neuronal synaptic plasticity improvement (Figure 3). Additionally, HPA axis regulation, neurotransmitter release, and receptor improvement $\left(\mathrm{A}_{2 \mathrm{~A}} \mathrm{R}, \mathrm{NMDA}-\mathrm{R}, \mathrm{GluR}\right.$, and AMPA-R) contribute to the potential therapeutic profile.

Perhaps the most important value of these findings is to show a scientific basis to promote the development of a drug candidate. Increasing evidence shows that a single molecular target cannot account for all the pathophysiological features in a given neurological disease, and RP seemingly affects many targets relevant to synaptic plasticity, neurogenesis, neuroprotection, and neural transmission, among others. Though molecular and cellular mechanisms of action still need elaboration, it is essential to investigate the neuroprotective effects using pharmacological models with translational value to unravel and assess its therapeutic potential.

\section{AUTHOR CONTRIBUTIONS}

All authors listed have made a substantial, direct, and intellectual contribution to the work and approved it for publication.

\section{FUNDING}

This work was supported by the Ministry of Science and Technology of China (2017ZX09301029), the National Key Research and Development Program (No. 2016YFE0131800), and the Development of Animal Model on Human Diseases (2016-I2M-2-006).

treatment gap for people with anxiety, mood, and substance use disorders: results from the WHO World Mental Health (WMH) surveys. Psychol Med. (2018) 48:1560-71. doi: 10.1017/S00332917170 03336

4. Yrondi A, Brauge D, LeMen J, Arbus C, Pariente J. Depression and sports-related concussion: a systematic review. Presse Med. (2017) 46:890902. doi: 10.1016/j.lpm.2017.08.013

5. GBD 2015 Disease and Injury Incidence and Prevalence Collaborators. Global, regional, and national incidence, prevalence, and years lived with disability for 310 diseases and injuries, 1990-2015: a systematic analysis for the Global Burden of Disease Study 2015. Lancet. (2016) 388:1545602. doi: 10.1016/S0140-6736(16)31678-6 
6. Xie W-J, Meng X-B, Zhai Y-D, Zhou P, Ye T-Y, Wang Z, et al. Panax notoginseng saponins: a review of its mechanisms of antidepressant or anxiolytic effects and network analysis on phytochemistry and pharmacology. Molecules. (2018) 23:940. doi: 10.3390/molecules23040940

7. Kim HJ, Kim P, Shin CY. A comprehensive review of the therapeutic and pharmacological effects of ginseng and ginsenosides in central nervous system. J Ginseng Res. (2013) 37:8-29. doi: 10.5142/jgr.2013.37.8

8. Nah SY, Kim DH, Rhim H. Ginsenosides: are any of them candidates for drugs acting on the central nervous system? CNS Drug Rev. (2007) 13:381404. doi: 10.1111/j.1527-3458.2007.00023.x

9. Wang Y-L, Liu J, Zhang Z-M, Bi P-X, Qi Z-G, Zhang C-D, et al. Anti-neuroinflammation effect of ginsenoside $\mathrm{Rbl}$ in a rat model of Alzheimer disease. Neurosci Lett. (2011) 487:70-2. doi: 10.1016/j.neulet.2010. 09.076

10. Liu L, Hoang-Gia T, Wu H, Lee Mi-Ra, Gu L-Juan, Wang C-Y, et al. Ginsenoside Rbl improves spatial learning and memory by regulation of cell genesis in the hippocampal subregions of rats. Brain Res. (2011) 1382:14754. doi: 10.1016/j.brainres.2011.01.051

11. Hong F, Wang L-J, Wu SL, Tang HC, Sha O, Wai Maria SM, et al. A review of three commonly used herbs which enhance memory and new evidences which show their combination could improve memory in young animals. Mini Rev Med Chem. (2017) 17:1537-47. doi: 10.2174/13895575166661609191 64352

12. Li C, Yang J, Yu S, Chen N, Xue W, Hu J, et al. Triterpenoid saponins with neuroprotective effects from the roots of Polygala tenuifolia. Planta Med. (2008) 74:133-41. doi: 10.1055/s-2008-1034296

13. Xu B, Qu C, Zheng W, Xi Y-Y, Zhao X, Li H-F, et al. UHPLC-MS/MS method for simultaneous determination of Radix Polygalae glycolipids and organic acids in rat plasma and application in a pharmacokinetic study. J Chromatogr B Analyt Technol Biomed Life Sci. (2018) 1100-1:16573. doi: 10.1016/j.jchromb.2018.09.037

14. Lv C, Li Q, Zhang $\mathrm{X}, \mathrm{He} \mathrm{B}, \mathrm{Xu} \mathrm{H}$, Yin $\mathrm{Y}$, et al. Simultaneous quantitation of polygalaxanthone III and four ginsenosides by ultrafast liquid chromatography with tandem mass spectrometry in rat and beagle dog plasma after oral administration of Kai-Xin-San: application to a comparative pharmacokinetic study. J Sep Sci. (2014) 37:110310. doi: $10.1002 /$ jssc. 201400058

15. Zhou P, Xie W, He S, Sun Y, Meng X, Sun G, et al. Ginsenoside Rb1 as an anti-diabetic agent and its underlying mechanism analysis. Cells. (2019) 8:204. doi: 10.3390/cells8030204

16. Sun Q, Meng Q-T, Jiang Y, Liu H-M, Lei S-Q, Su W-T, et al. Protective effect of ginsenoside $\mathrm{Rb} 1$ against intestinal ischemiareperfusion induced acute renal injury in mice. PLOS ONE. (2013) 8:e80859. doi: 10.1371/journal.pone.0080859

17. Klein-Júnior L, Andrade S, Cechinel Filho V. Cheminform abstract: a pharmacognostic approach to the polygala genus: phytochemical and pharmacological aspects. Chem Biodivers. (2012) 9:181-209. doi: 10.1002/cbdv.201000319

18. Xie W, Zhou P, Sun Y, Meng X-B, Dai Z-R, Sun G-B, et al. Protective effects and target network analysis of ginsenoside $\operatorname{Rg} 1$ in cerebral ischemia and reperfusion injury: a comprehensive overview of experimental studies. Cells. (2018) 7:270. doi: 10.3390/cells7120270

19. Shi T, Jiang Y. Isolation of flavonoids from the aerial parts of Polygala tenuifolia willd and their antioxidant activities. J Chin Pharmaceut Sci. (2013) 36-9. 22. doi: 10.5246/jcps.2013.01.004

20. Xu LL, Li CJ, Yang JZ, Luo YM, Zhang DM. Chemical constituents of Polygala tenuifolia root. J Chin Med Mater. (2014) 37:1594-6. doi: 10.13863/j.issn1001-4454.2014.09.022

21. Yang $C$, Yin $X$, Dong $X$, Zhang $X$, You LT, Wang WP, et al. Determination of the phytochemical composition of Jingning fang and the in vivo pharmacokinetics of its metabolites in rat plasma by UPLCMS/MS. J Chromatogr B Analyt Technol Biomed Life Sci. (2017) 1067:7188. doi: 10.1016/j.jchromb.2017.09.019

22. Shi Q-Y, Chen J-L, Zhou Q-F, Lei H-L, Luan L-J, et al. Indirect identification of antioxidants in Polygalae Radix through their reaction with 2,2-diphenyl-1-picrylhydrazyl and subsequent HPLC-ESI-QTOF-MS/MS. Talanta. (2015) 144:830-5. doi: 10.1016/j.talanta.2015. 07.032
23. Miyase T, Noguchi H, Chen XM. Sucrose esters and xanthone Cglycosides from the roots of Polygala sibirica. J Nat Prod. (1999) 62:9936. doi: 10.1021/np990084t

24. Zhou Y-F, Yan M-Z, Pan R-L, Wang Z, Tao X, Li C-C, et al. Radix Polygalae extract exerts antidepressant effects in behavioral despair mice and chronic restraint stress-induced rats probably by promoting autophagy and inhibiting neuroinflammation. J Ethnopharmacol. (2021) 265:113317. doi: 10.1016/j.jep.2020.113317

25. Zhao X, Cui Y-L, Wu P, Zhao P, Zhou Q, Zhang ZH, et al. Polygalae Radix: a review of its traditional uses, phytochemistry, pharmacology, toxicology, and pharmacokinetics. Fitoterapia. (2020) 147:104759. doi: 10.1016/j.fitote.2020.104759

26. Xu R, Mao FY, Zhao YS, Wang WP, Fan LL, Gao XJ, et al. UPLC quantitative analysis of multi-components by single marker and quality evaluation of Polygala tenuifolia wild. Extracts. Molecules. (2017) 22:2276. doi: 10.3390/molecules 22122276

27. Cao Q, Jiang Y, Cui SY, Tu PF, Chen YM, Ma XL, et al. Tenuifolin, a saponin derived from Radix Polygalae, exhibits sleep-enhancing effects in mice. Phytomedicine. (2016) 23:1797-805. doi: 10.1016/j.phymed.2016. 10.015

28. Yao Y, Jia Min, Wu J-G, Zhang H, Sun L-N, Chen W-S, et al. Anxiolytic and sedative-hypnotic activities of polygalasaponins from Polygala tenuifolia in mice. Pharm Biol. (2010) 48:801-7. doi: 10.3109/13880200903280042

29. Shin EJ, Oh KW, Kim KW, Kwon YS, Jhoo JH, Jhoo WK, et al. Attenuation of cocaine-induced conditioned place preference by Polygala tenuifolia root extract. Life Sci. (2004) 75:2751-64. doi: 10.1016/j.lfs.2004.04.045

30. Liu P, Hu Y, Guo DH, Wang DX, Tu HH, Ma L, et al. Potential antidepressant properties of Radix Polygalae (Yuan Zhi). Phytomedicine. (2010) 17:7949. doi: 10.1016/j.phymed.2010.01.004

31. Shin IJ, Son SU, Park H, Kim Y, Park SH, Swanberg K, et al. Preclinical evidence of rapid-onset antidepressant-like effect in Radix Polygalae extract. PLoS ONE. (2014) 9:e88617. doi: 10.1371/journal.pone.0088617

32. Jin ZL, Gao N, Zhang JR, Li XR, Chen HX, Xiong J, et al. The discovery of Yuanzhi-1, a triterpenoid saponin derived from the traditional Chinese medicine, has antidepressant-like activity. Prog Neuropsychopharmacol Biol Psychiatry. (2014) 53:9-14. doi: 10.1016/j.pnpbp.2014.02.013

33. Hu Y, Liu M, Liu $P$, Guo DH, Wei RB, Rahman $K$, et al. Possible mechanism of the antidepressant effect of 3,6'-disinapoyl sucrose from Polygala tenuifolia Willd. J Pharm Pharmacol. (2011) 63:869-74. doi: 10.1111/j.2042-7158.2011.01281.x

34. Hu Y, Liao HB, Liu P, Guo DH, Rahman K. A bioactive compound from Polygala tenuifolia regulates efficiency of chronic stress on hypothalamicpituitary-adrenal axis. Pharmazie. (2009) 64:605-8. doi: 10.1691/ph.2009.9580

35. Li Z, Liu Y, Wang L, Liu X, Chang Q, Guo Z, et al. Memory-enhancing effects of the crude extract of Polygala tenuifolia on aged mice. Evid Based Complement Alternat Med. (2014) 2014:392324. doi: 10.1155/2014/392324

36. Park H, Kang S, Nam E, Suh YH, Chang KA. The protective effects of PSM-04 against beta amyloid-induced neurotoxicity in primary cortical neurons and an animal model of Alzheimer's disease. Front Pharmacol. (2019) 10:2. doi: 10.3389/fphar.2019.00002

37. Sun XL, Ito H, Masuoka T, Kamei C, Hatano T. Effect of Polygala tenuifolia root extract on scopolamine-induced impairment of rat spatial cognition in an eight-arm radial maze task. Biol Pharm Bull. (2007) 30:172731. doi: 10.1248/bpb.30.1727

38. Guo C, Shen J, Meng Z, Yang X, Li F. Neuroprotective effects of polygalacic acid on scopolamine-induced memory deficits in mice. Phytomedicine. (2016) 23:149-55. doi: 10.1016/j.phymed.2015.12.009

39. Wei S. Potential therapeutic action of natural products from traditional Chinese medicine on Alzheimer's disease animal models targeting neurotrophic factors. Fundam Clin Pharmacol. (2016) 30:490-501. doi: 10.1111/fcp. 12222

40. Liu YM, Li ZY, Hu H, Xu SP, Chang Q, Liao YH, et al. Tenuifolin, a secondary saponin from hydrolysates of polygalasaponins, counteracts the neurotoxicity induced by Abeta25-35 peptides in vitro and in vivo. Pharmacol Biochem Behav. (2015) 128:14-22. doi: 10.1016/j.pbb.2014.11.010

41. Yu L, Sun L, Chen S. Protective effect of senegenin on splenectomy-induced postoperative cognitive dysfunction in elderly rats. Exp Ther Med. (2014) 7:821-6. doi: 10.3892/etm.2014.1501 
42. Jia $\mathrm{H}$, Jiang $\mathrm{Y}$, Ruan $\mathrm{Y}$, Zhang $\mathrm{Y}$, Ma $\mathrm{X}$, Zhang J, et al. Tenuigenin treatment decreases secretion of the Alzheimer's disease amyloid beta-protein in cultured cells. Neurosci Lett. (2004) 367:123-8. doi: 10.1016/j.neulet.2004.05.093

43. Ikeya Y, Takeda S, Tunakawa M, Karakida H, Toda K, Yamaguchi T, et al. Cognitive improving and cerebral protective effects of acylated oligosaccharides in Polygala tenuifolia. Biol Pharm Bull. (2004) 27:10815. doi: 10.1248/bpb.27.1081

44. Wang L, Jin GF, Yu HH, Lu XH, Zou ZH, Liang JQ, et al. Protective effects of tenuifolin isolated from Polygala tenuifolia Willd roots on neuronal apoptosis and learning and memory deficits in mice with Alzheimer's disease. Food Funct. (2019) 10:7453-460. doi: 10.1039/C9FO00994A

45. Fan Z, Liang Z, Yang $H$, Pan Y, Zheng Y, Wang X. Tenuigenin protects dopaminergic neurons from inflammation via suppressing NLRP3 inflammasome activation in microglia. J Neuroinflammation. (2017) 14:256 doi: 10.1186/s12974-0171036-x

46. Bae N, Chung S, Kim HJ, Cha JW, Oh H, Gu MY, et al. The neuroprotective effect of modified Yeoldahanso-tang via autophagy enhancement in models of Parkinson's disease. J Ethnopharmacol. (2011) 134:313-22. doi: 10.1016/j.jep.2010.12.016

47. Bae N, Chung S, Kim HJ, Cha JW, Oh H, Gu MY, et al. Neuroprotective effect of modified Chungsimyeolda-tang, a traditional Korean herbal formula, via autophagy induction in models of Parkinson's disease. J Ethnopharmacol. (2015) 159:93-101. doi: 10.1016/j.jep.2014.11.007

48. Liu X, Wang D, Zhao R, Dong X, Hu Y, Liu P. Synergistic neuroprotective effects of two herbal ingredients via creb-dependent pathway. Front Pharmacol. (2016) 7:337. doi: 10.3389/fphar.2016. 00337

49. Wei PJ, Yao LH, Dai D, Huang JN, Liu WX, Xiao P, et al. Tenuigenin enhances hippocampal Schaffer collateral-CA1 synaptic transmission through modulating intracellular calcium. Phytomedicine. (2015) 22:807-12. doi: 10.1016/j.phymed.2015.05.008

50. Pi T, Zhou XW, Cai L, Zhang W, Su CF, Wu WT, et al. PI3K/Akt signaling pathway is involved in the neurotrophic effect of senegenin. Mol Med Rep. (2016) 13:1257-62. doi: 10.3892/mmr.2015.4652

51. Dong XZ, Huang CL, Yu BY, Hu Y, Mu LH, Liu P, et al. Effect of Tenuifoliside A isolated from Polygala tenuifolia on the ERK and PI3K pathways in C6 glioma cells. Phytomedicine. (2014) 21:117888. doi: 10.1016/j.phymed.2014.04.022

52. Hu Y, Liu MY, Liu P, Dong X, Boran AD. Neuroprotective effects of 3,6'-disinapoyl sucrose through increased BDNF levels and CREB phosphorylation via the CaMKII and ERK1/2 pathway. J Mol Neurosci. (2014) 53:600-7. doi: 10.1007/s12031-0130226-y

53. Park HJ, Lee K, Heo H, Lee M, Kim JW, Whang WW, et al. Effects of Polygala tenuifolia root extract on proliferation of neural stem cells in the hippocampal CA1 region. Phytother Res. (2008) 22:1324-9. doi: 10.1002/ptr. 2488
54. Lee HJ, Ban JY, Koh SB, Seong NS, Song KS, Bae KW, et al. Polygalae radix extract protects cultured rat granule cells against damage induced by NMDA. Am J Chin Med. (2004) 32:599-610. doi: 10.1142/S0192415X04002235

55. Kim HM, Lee EH, Na HJ, Lee SB, Shin TY, Lyu YS, et al. Effect of Polygala tenuifolia root extract on the tumor necrosis factor-alpha secretion from mouse astrocytes. J Ethnopharmacol. (1998) 61:2018. doi: 10.1016/S0378-8741(98)00040-3

56. Kim KS, Lee DS, Bae GS, Park SJ, Kang DG, Lee HS, et al. The inhibition of JNK MAPK and NF-kappaB signaling by tenuifoliside A isolated from Polygala tenuifolia in lipopolysaccharide-induced macrophages is associated with its anti-inflammatory effect. Eur J Pharmacol. (2013) 721:267-76. doi: 10.1016/j.ejphar.2013.09.026

57. Lv H, Ren W, Zheng Y, Wang L, Lu G, Yi P, et al. Tenuigenin exhibits anti-inflammatory activity via inhibiting MAPK and NF-kappaB and inducing Nrf2/HO-1 signaling in macrophages. Food Funct. (2016) 7:35563. doi: 10.1039/C5FO00807G

58. Cheong MH, Lee SR, Yoo HS, Jeong JW, Kim GY, Kim WJ, et al. Antiinflammatory effects of Polygala tenuifolia root through inhibition of NFkappaB activation in lipopolysaccharide-induced BV2 microglial cells. $J$ Ethnopharmacol. (2011) 137:1402-8. doi: 10.1016/j.jep.2011.08.008

59. Le TK, Jeong JJ, Kim DH. Clionosterol and ethyl cholestan22-enol isolated from the rhizome of Polygala tenuifolia inhibit phosphatidylinositol 3-kinase/Akt pathway. Biol Pharm Bull. (2012) 35:1379-83. doi: 10.1248/bpb.b12-00426

60. Jia R, Zhang H, Zhang W, Zhao H, Zha C, Liu Y. Protective effects of tenuigenin on lipopolysaccharide and d-galactosamine-induced acute liver injury. Microb Pathog. (2017) 112:83-88. doi: 10.1016/j.micpath.2017.09.051

61. Lenart N, Brough D, Denes A. Inflammasomes link vascular disease with neuroinflammation and brain disorders. J Cereb Blood Flow Metab. (2016) 36:1668-85. doi: 10.1177/0271678X16662043

Conflict of Interest: The authors declare that the research was conducted in the absence of any commercial or financial relationships that could be construed as a potential conflict of interest.

Publisher's Note: All claims expressed in this article are solely those of the authors and do not necessarily represent those of their affiliated organizations, or those of the publisher, the editors and the reviewers. Any product that may be evaluated in this article, or claim that may be made by its manufacturer, is not guaranteed or endorsed by the publisher.

Copyright (c) 2021 Jiang, Wei, Zhang, He, Pei, Huang, Wang and Liu. This is an open-access article distributed under the terms of the Creative Commons Attribution License (CC BY). The use, distribution or reproduction in other forums is permitted, provided the original author(s) and the copyright owner(s) are credited and that the original publication in this journal is cited, in accordance with accepted academic practice. No use, distribution or reproduction is permitted which does not comply with these terms. 